\title{
Gaining Institutional Permission: Researching Precarious Legal Status in Canada
}

\author{
Judith K. Bernhard
}

Ryerson University

Julie E. E. Young

Ryerson University

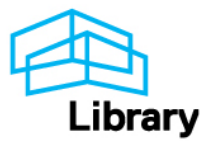




\title{
Gaining Institutional Permission: \\ Researching Precarious Legal Status in Canada
}

\author{
Judith K. Bernhard \\ Ryerson University \\ Julie E.E. Young \\ York University \\ Paper submitted to the Journal of Academic Ethics
}

October 23, 2009

\section{Corresponding Author:}

Judith K. Bernhard, Ph.D.

Professor and Director of Graduate Program

School of Early Childhood Education, Ryerson University

350 Victoria Street, Toronto, ON M5B 2K3 Canada

Tel: 416-979-5000, ext. 7647

Email: bernhard@ryerson.ca 
Researching Precarious Legal Status 2

\begin{abstract}
There is limited research into the situations of people living with precarious status in Canada, which includes people whose legal status is in-process, undocumented, or unauthorized, many of whom entered the country with a temporary resident visa, through family sponsorship arrangements, or as refugee claimants. In 2005, a community-university alliance sought to carry out a research study of the lived experiences of people living with precarious status. In this paper, we describe our negotiation of the ethics review process at a Canadian university and the ethical, legal, and methodological issues that emerged. Although being able to guarantee our participants complete confidentiality was essential to the viability of the project due to their vulnerability to detention or deportation, we discovered that the Canadian legal framework limited us to being able to offer them confidentiality "to the fullest extent possible by law." One way to overcome this conflict would have been through the construction of a Wigmore defence, in which we would document that the research would not be possible without assurance of our participants' confidentiality. Such a defence would be tested in court if our research records were subpoenaed by immigration enforcement authorities. Rather than take the risk that this defence would not be successful and would result in our participants being deported, we altered the research methods from using multiple interviews to establish trust (which would have required that we store participants' contact information) to meeting participants only once to discuss their experiences of living with precarious legal status in Canada. Our encounter with the "myth of confidentiality' raised questions about the policing of knowledge production.
\end{abstract}




\section{Gaining Institutional Permission:}

\section{Researching Precarious Legal Status in Canada}

Canadian life is affected by thousands of men, women, and children living in the country with precarious or less than full legal status. However, facts about this large segment of the Canadian population are largely unknown. Research into the realities of life for those without full legal status in Canada would have far-reaching implications for all Canadian residents. However, in the absence of this research, Canadian citizens, service providers, government bodies, and immigrants are currently encumbered by a major blind spot. This handicap is further complicated by the large-scale ignorance and misconceptions that exist surrounding this issue.

For instance, few people realize how many residents -- including families with young children-- live permanently in Canada with varying gradations of legal status. Apart from the approximately 250,000 immigrants admitted to Canada every year, there are many people who arrive without permanent legal status as well. 2007 saw enough temporary workers to staff 1,800 farms enter through the Seasonal Agricultural Workers Program. An additional 4,000 women came into the country under the Live-in Caregiver Program. Despite the 'temporary' label that was ascribed to them through the immigration process, many of these individuals remain in the country long-term or return year after year.

Many people also cross the border into Canada on student visas, tourist visas, or as refugee claimants -- and then end up overstaying their visas, going underground after failed refugee claims, failing to show up at their deportation hearings, and so on. Although there are no accurate figures available to indicate how many people are living in Canada with precarious status, estimates range from 
40,000 to 600,000 individuals (Jimenez, 2003; Khandor, McDonald, Nyers, \&

Wright, 2004; Robertson, 2005; Wright, 2003).

Research into the lives of these residents is relevant to all Canadian citizens because no resident exists in a vacuum- the lives of people in a community are all inter-related. For instance, regardless of legal status, if any resident has TB and fears accessing healthcare to report their condition, then citizens and non-citizens alike are at risk of exposure. Several studies have found that people living with precarious legal status in Canada are hesitant to seek out medical attention unless in emergency or acute situations. As a result, these residents do not benefit from preventative healthcare (Access Alliance Multicultural Community Health Clinic, 2005; Bannerman, Hoa, \& Male, 2003; Committee for Accessible AIDS Treatment, 2001). Research like this is relevant to everyone in the community.

Research into the lives of residents with precarious status is important for governments and service providers as well. For example, this research is needed in order for governments to ensure they are not contravening Canada's legal obligations as a signatory to such international instruments as the United Nations Convention on the Rights of the Child (1990) which guarantees a range of rights to children under age 18 regardless of their status ${ }^{1}$. Governments would also benefit from having a sense of the prevalence of the issues not only to determine funding levels needed for organizations such as child protection and police agencies, but also to mitigate sensationalized reports of 'floods' of 'illegals' taking advantage of the state's resources (Bean et al., 2001). Moreover, several studies urge us to

\footnotetext{
${ }^{1}$ This is particularly important given numerous examples of violations of children's rights that were presented at the recent international conference on undocumented migrants (Platform for International Cooperation on Undocumented Migrants, 2009).
} 
consider how such social implements as temporary work programs create bridges to precarious status (Goldring, Berinstein, and Bernhard, 2009; Valiani, 2009). In addition, it is important to consider the impact of policies on individual and collective wellbeing. Living with a sense of exclusion is detrimental to people's health (Hall \& Lamont, 2009).

Service providers and others with whom less-than-full-status residents come into contact need research in this area because their professional competence may depend on it. For example, social service providers would be aided by the knowledge that many women's refusal to leave abusive spouses may be due to fear that this will disrupt the immigration sponsorship process (DADT, 2005; San Martin, 2004; Schwenken, 2003). Health centre workers could do a better job if they knew that many pregnant women with precarious status believe that their children will be apprehended when born. They would be able to help these women safely register their children with authorities so that their children would not be denied access to the rights that they are entitled to as Canadian citizens.

This research is certainly relevant towards improving the lives of those living with precarious legal status as well. The role of fear in limiting their choices has been documented yet the general public is often not aware of their difficulties or even their existence (Berinstein, McDonald, Nyers, Wright, \& Zerehi, 2006; Berk \& Schur, 2001; Lessard \& Ku, 2003; Schwenken 2003; Yau 1995). Their limited legal status prevents them from obtaining a social insurance number needed to work legally, gaining access to healthcare, or affordably accessing the childcare to postsecondary education systems. Access to the social safety net that other residents take for granted is effectively denied them, including such basic services as being able respond to child protection agencies that try to apprehend their child, or even 
Researching Precarious Legal Status 6

to call the police or the fire department if a life is in danger. Their precarious legal status makes people hesitant and even fearful to make themselves known to authorities.

Perhaps most importantly, it is essential to pay attention to how the state treats non-citizens because this treatment leaves citizens not as safe as their formal legal status would have them believe they are. As Arat-Koc (1992) contends, it is “difficult to use certain discourses for 'others' without having implications for 'self'”'(p. 240). The treatment of non-citizens can very easily become the treatment of citizens, especially citizens who are marginalized for other reasons than legal status. When the rights of some members of society are restricted, everyone must pay attention.

\section{Barriers to Research}

Despite the importance of conducting research in this area, efforts to do so are stymied on many fronts. In Canada, most research in the field has focused on state practices of border control (Macklin, 2001; Nyers, 2003; Walters, 2002) and the economic insecurity faced by those living without full legal status (Pratt \& The Philippine Women Centre, 2003; Sharma, 2006; Stasiulis \& Bakan, 2005). A few studies have outlined the challenges faced by people living with precarious legal status in accessing healthcare and other social services (AAMCHC, 2005; Bannerman et al, 2003; Berinstein et al, 2006; CAAT, 2001) but these have focused mostly on the perspectives of service providers rather than the people affected. There is very little documentation of the everyday lived experiences of people who are made insecure through the narrowing of borders for secure permanent residence in Canada. In particular, little is known about the situations of families and children who are living precariously (but see Bernhard, Goldring, Young, Wilson, \& 
Berinstein, 2007; Young, 2005).

One primary factor discouraging research is the fact that few people realize the issue of legal status cannot be boiled down to a simple 'us-and-them' paradigm where some residents are legally documented and others hide from the authorities in a shady, little-known underworld. Recent work in migration studies has elaborated upon the concept of legal status, showing it to be a complicated, multilayered, and multi-actor process that does not exist in a straightforward legal-illegal or documented-undocumented binary (de Genova, 2002; Goldring, Berinstein, \& Bernhard, 2009; Menjivar, 2006), but many people still use the dichotomies of legal versus illegal. As expected, the public has varying opinions on the topic, to the extent that some will say that because these people did not go through 'appropriate immigration channels,' they do not deserve empathy or consideration.

This perspective influences law-makers but fails to appreciate that in reality legal status tends to move along a continuum with individuals shifting from one legal status to another over a period of years or decades. In most cases in Canada, people do arrive through formal channels and for various reasons may lose or fall out of status. Especially when children are involved, we must take the high road and focus on children's wellbeing rather than on judging the moral correctness of their parents' or other adult individuals' actions. The problem worsens as shortterm legal solutions such as detention and deportation are enacted in ignorance of their long-term repercussions for the countries' migrant population, including minors.

For example, as Canada narrows its borders for secure permanent residence and increasingly relies on temporary labour arrangements to meet the needs of particular industries, the number of Canadians with precarious legal status is 
Researching Precarious Legal Status 8

growing. In 2007, in response to the reported shortage of workers in the oil industry and in anticipation of the Vancouver 2010 Olympics, Canada opened 12 new occupations to temporary workers in Alberta and British Columbia (CBC Radio, 2008). A condition for many of these temporary work programs is that the person's visa is only valid if they stay with the original employer who sponsored them. Because of abusive and uneven power relations, many temporary workers are forced to leave their employers and this leads them directly into living with precarious status (e.g., Sharma, 2006; Valiani, 2009).

There are many other examples of legal trapdoors leading adults into situations of precarious legal status as well, but worse still are examples involving children. For instance, for children who have status protections while they are Crown Wards of Children's Aid Societies, that status and those protections are abruptly revoked when they reach the age of maturity (Hare, 2007). "How does a child incorporate the notion that she is an alien, or an illegal - that she is unwanted and does not warrant the most basic rights of education and health care?," ask researchers Suárez-Orozco and Suárez-Orozco (2001, p.7). To convey the complex ways in which status works, in this paper we use the terms less-than-full-status or precarious status (Goldring et al., 2009).

Public opinion misinformed by ignorance deters research, but of greater concern is that researching the lives of Canadian residents with precarious legal status is limited by a legal and academic system in gridlock. Though the issue of misinformation might be addressed through public education, this cannot be accomplished unless the academic community is encouraged to challenge the status quo through the accumulation of new data and alternate conclusions. A series of factors currently come together to bar academic researchers from engaging in this 
important field.

Though academics may be interested in contributing their time and resources towards researching the lives of residents living with precarious legal status, legal provisions which are the focus of this paper curtail research method extensively. These restrictions frustrate efforts at data collection and raise questions about career advancement; as a result, few researchers are sufficiently motivated to devote their time to these issues. Many stakeholders in the research process are not aware of the challenges that arise in the lives of people living with precarious legal status. As the size of this population increases, these problems increase in kind. Canada cannot afford to discourage research into these areas, yet that is exactly the situation created by the clash between Canada's legal and academic systems as they stand today.

Though our attempts to carry out two research projects involving participants with precarious legal status met with much resistance, they provided apt illustration of a system in need of change. Drawing from these experiences, this paper discusses the ethical, legal, and methodological issues we encountered ${ }^{2}$. Our conclusions comment on potential changes to the research approval system that might better support research into the lives of Canadian residents living with precarious legal status.

\section{Original Research Plans}

Researching the lives of Canadian residents without full legal status has sparked the interest of several groups over the last decade. In 2002, a partnership

\footnotetext{
${ }^{2}$ Please note that in this paper we are not reporting on the results of the two studies regarding the actual experiences of participants but rather on the research-related issues; for those discussions, please see Bernhard et al (2007) and Young (2005; forthcoming).
} 
Researching Precarious Legal Status 10 was developed between investigators at three universities and a coalition of service providers including a community health centre, a refugee shelter, and a legal clinic in four southwestern Ontario cities. The goal was to collaborate on a research project that would document the extent of the phenomenon of precarious legal status in these cities as well as provide insight into the effects of living long-term in Canada with such status.

These data were intended to fill a substantial void in understanding the experiences and issues faced by this population. Our goals included increased public knowledge about the factors contributing to precarious legal status in this country, and the hope that this knowledge might motivate local residents in efforts to help children and families in these situations. We hoped that existing campaigns would be strengthened and that the demand for necessary reforms to improve the system would be increased. Similarly, we trusted that this research would aid governments in their appreciation of the scope and nature of these problems. Ministers would be encouraged to acknowledge that these issues are of substantial proportions and address the service provision gaps.

Our project began with preliminary meetings between investigators and service providers. Dozens of service providers assured us that many of their clients would be willing to talk about their challenges and hopes in a formal interview with the research team. Moreover, ten organizations, three universities and a private family foundation committed to providing substantial in-kind donations that included meeting space, staff time, and translation costs. This tremendous expression of support on the part of the service providers and community agencies was due to their belief that if data were available, they could be used to advocate for the individuals and families with whom they work. 
Researching Precarious Legal Status 11

Over the next two years, the team met sixteen times to develop a proposal for a systematic study of people living with precarious status in Ontario. Our plan was based around a mixed-methods study that would include 1700 surveys and 250 indepth interviews with both individuals living with uncertain status and the 'institutional actors'--such as service providers, religious leaders, union organizers, and teachers-with whom they came into contact. At the same time, a Master's student who became affiliated with this project developed a project that would use semi-structured, open-ended interviews to focus on how youth experience living with precarious status in Toronto (Young, 2005).

The team drafted and was awarded a developmental grant by the Social Sciences and Humanities Research Council (SSHRC) of Canada. The grant was awarded towards the testing of the survey and interview protocols. We also sought to refine and solidify the process of working through a diverse number of community agencies to gain access to the various types of people living with precarious legal status. For example, besides those who came forth to access the services of community agencies, we also wanted to include isolated families or those living in transnational family arrangements.

The letter of award from SSHRC included glowing remarks about the methods and the need for research in this area. The reviewers identified the following strengths: "Important topic as very little research has been done in the area; specific, detailed methodology; good team of researchers; strong partnership." The research team was energized to see that the collaboration with the community agencies would finally be possible.

\section{Anticipated Challenges}

Our team anticipated the challenges that might arise in carrying out a project 
Researching Precarious Legal Status 12 with people living with precarious legal status. Gaining the trust of 'invisible' people who wish to stay below the radar of government authorities is tricky and we deliberated on each of the challenges and found ways to address each one.

First was the issue of how to build trust with participants. The research team was aware that people who fear detention or deportation would need time to determine who can be trusted. We anticipated that people would be hesitant to participate or reluctant to answer questions when the immediate benefit to themselves was unclear. As a result, we planned to make extensive efforts to foster the kind of continuity and sensitivity in researcher-participant relations that was seen as crucial to good data collection (Cornelius, 1982). In order to do that, the focus of the first two sessions would be on asking the participants questions about their migration experiences. For example, we planned on asking how they decided when and where to migrate. Was there someone in their family that had moved abroad before? We also planned to talk about their networks-- who were the significant people in their lives? Where did they live? Were these ties weakened by immigration or maintained? In this manner, the questions about hardships could be saved until the third or fourth interview session when a degree of trust had been established.

Another challenge was how to balance the recruitment help of community agencies with the potential that people might feel pressured to participate. We wanted to avoid a situation where involvement of people from organizations might be perceived as potentially affecting an individual's future relationship with that organization. We therefore resolved that service providers would not know which of their clients ended up participating in the study. Participants would be clearly informed of this procedure. 
Researching Precarious Legal Status 13

We carefully considered the issue of consent forms given that highly legalistic and complicated informed consent documents have been known to affect response rates (Greyson \& Miles, 2005). The normal practice for academic researchers is to use written consent forms that include the participant's signature. This allows for independent verification at a later date that participants formally agreed to participate. Further, it is an indication that they were not deceived, pressured, or given undue enticements to participate. However, due to the focus on precarious legal status, it was essential that we take particular precautions to protect the identities of the participants so that a list of their names and phone numbers would not end up in the hands of those authorities who could deport participants.

In order to avoid this, we planned to offer participants their choice of a verbal or written consent process. For those individuals who would choose to give their consent verbally, we proposed to use a pseudonym to initial the document beside the place where they indicated they had agreed to a verbal process. In this manner, though their contact information would remain accessible to us for follow-up purposes, study participants would be identifiable to no one but ourselves. To further bolster a sense of trust, we would provide them with a copy of the consent agreement that they could keep. Codes would be used when storing participants' information so that their identities would be known only to those on the research team.

We further anticipated that asking participants to recount difficult personal experiences would involve risks as well. As researchers, we knew how important it was to be attentive to the psychological and emotional effects on individuals of recounting their personal stories and fears. Participating in an interview or focus group in which one's migration trajectory or current situation is discussed might 
Researching Precarious Legal Status 14

feel similar to being interrogated by an immigration official. In order to address this challenge, the interview protocol was designed so as to provide a constant negotiation of what participants wanted to share. We also deliberated on the need to budget for a counsellor who could be available for interviewees who ended up distressed while recounting their experiences.

What we discovered later was that many of the challenges we anticipated with participants were not the main stumbling block in carrying out the research. Our concerns had revolved around the issue of how to gain trust and maintain it towards the collection of thorough and accurate data, but the main issue we encountered was that, under the system currently prevalent throughout North America, promising our participants complete confidentiality was a legal impossibility.

We wanted to be able to assure people that participating in our study would not put them at an increased risk of having an immigration official show up at their home or place of work. However, following repeated encounters with various bodies monitoring the university research process, we learned that under the current system to make such a promise would either involve misleading study participants or risking our own legal apprehension.

\section{Encountering the Ethics Review Board}

The first step in the research process was meeting with the Ethics Review Board. As the grant monies we had been awarded could not be released until the university's Ethics Review Board (ERB) had given their stamp of approval, we sent in our ERB application form expecting to begin research shortly.

Having funds reserved until approval by an ethics review board is common university practice. Our university, like those in the rest of Canada and the US, is charged with developing an ethics review process in compliance with a statement 
Researching Precarious Legal Status 15

developed by the federal government. This Tri-Council Policy Statement ${ }^{3}$ sets the protocols and requirements for evaluating proposed research projects involving human subjects. Deriving from their concern with protecting research participants, this board had the authority to alter the project or even prevent it altogether. In most cases, projects considered by the ERB are approved, often with some adjustments to wording of informed consent documents or recruiting procedures.

Although these boards were initially established to address deceptive and unethical practices in medical research, the same standard application form is also used for projects in the social sciences and humanities. This has led recent publications to suggest that the reach of the ERB has become unwieldy as the ethics protocol may not be well suited to projects in the social sciences and humanities (Bledsoe, Sherin, Galinsky, Headley, Heimer, Kjeldgaard, Lindgren, Miller, Roloff, \& Uttal, 2007; Dyer \& Demeritt, 2009; Greyson \& Miles, 2005; Sikes \& Piper, 2008; Stark, 2006). Dyer and Demeritt (2009) argue that "the ethical frameworks applied by formal ethical review processes ignore... wider normative and political concerns at best, and at worst actively subvert ongoing efforts to infuse [research] practice with an ethical sensibility"(p.48). While we agree with their critique that successful negotiation of the formal ethical review process does not mean a researcher's approach or outcomes will be ethical (and vice versa), in our situation the ERB served to highlight legal issues that would have been problematic in our research regardless of their counsel.

In fact, the legal issues we or our participants were at risk of encountering became evident to the ERB immediately upon receipt of our application form. This

3 The Tri-Council consists of the Social Sciences and Humanities Research Council (SSHRC), the Natural Sciences and Engineering Research Council (NSERC), and the Canadian Institutes of Health Research (CIHR), which are the three major funding bodies for research in Canada. 
Researching Precarious Legal Status 16 form includes a section in which the researcher estimates the level of risk involved in participating in the project. In our applications, due to the focus on precarious legal status, we indicated that the participants faced 'more than minimal risk' by talking to us. The involvement of youth under age 18 in the second study was also noted. Although we reported the measures we planned to use to mitigate risks, noting that the project was more than minimal risk automatically initiated a more thorough approach to review of the project by the ethics board.

The response from the ERB to both projects was a lengthy letter asking us for clarification on a number of areas, most of which we had already considered. The main concern of board members was that if the researchers were in possession of the participants' contact information, there was a risk their information could be traced back to their identities. Even if pseudonyms and code numbers were used, having a list of participants' phone numbers put them at risk as researchers' records might be subpoenaed and the researchers ordered to disclose contact information to the Canada Border Services Agency (CBSA), the federal immigration enforcement agency.

The Board was also concerned that agency workers who recruited participants would be able to identify all the potential participants. This could place these service providers in a position where they would have to provide authorities with participants' contact information, increasing the risk faced by individuals who took part in the study even further. Understandably, this is always a concern for ethics boards when research and recruitment involves agencies or service providers on whom participants depend outside of the context of research.

The ERB and our group discussed options such as keeping the contact information in a separate location from the surveys or converting it into digital data. 
Given the sensitive nature of our topic, no one contested that complete confidentiality was essential, or that our duty in conducting such research included the ability to provide research participants with such an assurance. The ERB insisted that we could not promise complete confidentiality, only confidentiality permitted by law. It appeared that if we went ahead with multiple interviews, which would require that we collect and store contact information, there would be no way to unequivocally promise confidentiality to participants. Our proposal was the first to really push this question in the history of the university ${ }^{4}$.

Although we at first interpreted the ERB's response as adversarial, we soon realized that board members wanted to find a way to approve the proposal. Though the ERB wished to support innovative and important research, their approval depended on the ability to negotiate several mandates: the upholding of Canadian law, protecting research participants from risk, and protecting researchers from legal apprehension.

Finally, the ERB recommended that participants' consent forms be revised to include the following phrase: "Confidentiality will be provided to the fullest extent possible by law." We felt this coy turn of phrase would mislead study participants into a false sense of security. This 'myth of confidentiality', a promise of confidentiality to the extent bound by law, meant, in effect, no real confidentiality at all.

Our interactions with the ERB had been an introduction to a set of very uncomfortable choices. Were we to mislead study participants regarding the extent to which we could assure their confidentiality; promise to maintain their

4 Subsequent to our experience in 2005 , there have been several related projects approved by the ERB. 
confidentiality even if that promise took us to jail; minimize the scope of the project vastly in both data quality and data quantity; or abandon this area of research altogether? The ERB had made clear that gaining our study participants' trust with legal backing was not currently possible. We had met with the disturbing fact that for researchers wishing to study trends among North American populations whose whereabouts the government wishes to access $^{5}$ there is, as yet, no legal basis for promising absolute confidentiality.

\section{Considering the Wigmore Defence}

Our encounter with these issues prompted us to further investigate the issue of confidentiality in academic research. How had other researchers coped with these limitations that we had encountered? Would the legal system seek to apprehend representatives of the academic system engaging in research that could be clearly proven to be for the public good? To our dismay, we learned that these issues were far from hypothetical.

The fact was that researchers in a number of areas had been subpoenaed to produce their field notes in order to identify participants. For example, in 1971 a researcher was subpoenaed for his study about whether participants had collected welfare while receiving income maintenance in the US. Another of the cases that gave us pause was that of Samuel Popkin, a Harvard professor who was jailed for eight days in 1972 for refusing to reveal the identities of the people he interviewed for a secret war study (Lowman \& Palys, 2001). In 1973 the US Federal Bureau of Investigation threatened to subpoena the research records of the Kinsey Institute's

\footnotetext{
${ }^{5}$ The challenges of those working with immigrants with precarious status can be compared to the challenges faced by researchers working with drug addicts, individuals who provide assisted suicide, and interventions aimed at male clients of prostitutes, the so called 'john' schools, whose research participants might be of interest to various authorities. In these sensitive cases, the protection of the researchers' sources is paramount to thorough data collection.
} 
Researching Precarious Legal Status 19

work on human sexuality. We discovered that in some cases, upon failure to produce field notes, researchers had been jailed for several months at a time (Caroll \& Knerr, 1975; Lowman \& Palys, 2001). Most surprising to us were the cases where universities had not supported their researchers, allowing them to be sued and even to go to jail in spite of conducting the research as part of the terms of their employment.

Because we had been unable to come up with a way to resolve our research confidentiality problems in discussions with the ERB, we sought legal advice to access lawyers' greater familiarity with these legal issues. Our objective was to see whether any circumstances might permit us to be able to promise complete confidentiality while retaining participants' contact information. Understanding that this project focused on a vulnerable population, our main concern was to ensure that these individuals not be placed at any more risk than they already faced on a day-to-day basis due to their precarious legal status. It was in a consultation with lawyers at a Toronto firm that we found out about the so-called 'Wigmore' defense.

Our consultation with legal professionals informed us that the issue of confidentiality in research has been litigated in both the US and Canada. We learned that the murky area dealing with protection of researchers' sources has been addressed in several court procedures. Discussions revealed that the definitive decision-making apparatus around such questions in the US is what is called The Wigmore Test (Lempert \& Saltzburg, 1982; Lindgreen, 2002; Lowman \& Palys, 2001). This procedure, now followed in Canadian courts as well, allows researchers to protect the confidentiality of their sources under four conditions: 
Researching Precarious Legal Status 20

The communications must originate in a confidence that they will not be disclosed; This element of confidentiality must be essential to the full and satisfactory maintenance of the relation between the parties; The relation must be one which in the opinion of the community ought to be sedulously fostered; and the injury that would inure to the relation by the disclosure of the communications must be greater than the benefit thereby gained for the correct disposal of litigation (Wigmore, 1905, p. 3185; emphasis in original).

In other words, the researcher must be able to document that the results of the research and the interests of the participant are of greater importance than resolving a legal matter. The Wigmore defence does not contest the law, but claims that the litigant's research would benefit the community to the extent that it ought to be made an exception. In order to successfully meet the Wigmore test, researchers must show that the community can benefit from the research only if researchers are able to protect the confidentiality of participants.

A recent ruling in a national security case in Canada allowed the Wigmore defense in protecting the confidentiality of an informant to the Canadian Security Intelligence Service (CSIS). Federal Court Justice Simon Noel ruled that the CSIS informant who had provided evidence to the government in the case of Mohamed Harkat, detained under a security certificate since 2002 without knowing the content of the charges against him, could not be cross-examined by or identified to Harkat's legal team:

Justice Noel held that the relationship between CSIS and its covert human sources meets the conditions stipulated by Wigmore for recognizing a common law privilege. Covert sources are given absolute promises that their identities 
Researching Precarious Legal Status 21

will be protected. These confidentiality guarantees are essential to the ability of CSIS to fulfill its mandate to protect Canada's national security, while protecting the source from retribution (Schmitz, 2009).

In an interesting turn of events, due to issues with the credibility of the informant, the federal court has required CSIS to reveal the source's identity to a select group of people, thereby revoking the protection given under the Wigmore test (Curry, 2009).

In our case, the lawyers we consulted insisted we should anticipate Wigmore from the beginning of the research process and indicate that the research could not go ahead unless we were to promise confidentiality. For example, when starting the interview, the researcher should talk about confidentiality and specifically ask the participant, "If there was no promise of confidentiality, would you be willing to talk to me about this matter?" Recording that the promise of confidentiality was absolutely essential is good preparation for a Wigmore defense, we were told.

We sought further advice directly from Ted Palys, a colleague who had written extensively about the Wigmore defence. In response to our question about how to conduct research with participants whose legal status makes them vulnerable to detention and deportation, Palys agreed with the lawyers by suggesting that we should be "anticipating Wigmore from the start" and that taking actions like meeting with the full ERB, obtaining legal counsel, or consulting with him would be well regarded by a court as it showed that we had always acted as though confidentiality was essential:

Basically you should be thinking of 'evidence' and the creation of a record showing how much you are concerned about your participants, which you obviously are, and of the steps you are taking to ensure that your interactions 
Researching Precarious Legal Status 22

with them are as bulletproof as you can make them. This interchange between you and I [the email exchange] is similarly important insofar as it shows you are going as far as seeking expert advice on what to do. You should also make it clear in your interactions with the ERBs. Bottom line here is that it is pretty clear that everyone you are contacting recognizes that confidentiality is essential to gathering valid data and protecting the research participants, and that the project cannot happen, and the data will not exist for anyone's use (i.e., yours OR the court's) without it (Palys, 2005, personal communication).

Just to confirm whether we were truly at risk of encountering these legal issues, we decided to contact the Canadian Border Services Agency (CBSA) asking for a letter undertaking to respect the confidentiality that we would be promising our participants. We argued that although it was clear that the proposed research was for the public good, in order to conduct the study, we had to be able to assure participants that their responses were confidential and that their participation in this study would in no way trigger enforcement to investigate or deport them. The response that we received was that the agency was mandated to remove inadmissible persons from Canada as soon as is practical. Therefore, it would be contrary to the CBSA's legislative obligations to entertain the request not to pursue enforcement action of the study participants (Doiron, 2005, personal communication).

Our legal concerns had been confirmed. It seemed that if we followed the ERB suggestion to indicate that we could only assure confidentiality 'to the extent permitted by law,' we would fail the Wigmore ${ }^{6}$. If we said that we absolutely 
Researching Precarious Legal Status 23 guaranteed confidentiality and would be willing to go to jail to uphold it, we might meet the Wigmore criteria; however, this defence might or might not hold up in court. In other words, even if we risked going to jail for both our study participants and for the greater public good of conducting the research, we might promise confidentiality but not be able to deliver it.

\section{Our Compromised Research}

After all of these consultations with the ethics board, the lawyers, colleagues, and the CBSA, we understood that our hands were tied. In view of this, and despite our prior deliberations in developing the research proposal, we decided to reconsider our plan to engage in multiple interviews with people whose status was precarious. The ERB suggested that we consider changing the focus to participants who were at some point living with precarious status but had regularized their situations. We elected not to do this as it would entail a shift in focus from our proposed research on the situations of people currently living with precarious status.

In order to accommodate the demands of the situation, however, we scaled back our research plans and in 2005, conducted a study that surveyed 18 individuals living with precarious status recruited through ten entry points. The survey consisted of short-answer, closed questions and was administered by the research team in the language with which the participant was most comfortable. The interview protocol concluded with four open-ended questions to draw out further stories and details. The youth study, which had a shorter timeframe for completion, involved open-ended, semi-structured interviews with six participants recruited through four entry points.

The most significant compromise we made for both projects was not to collect 
Researching Precarious Legal Status 24

or store participants' names or contact information so that these details would not appear in our files. This meant that we had to abandon the idea of multi-interview research. Because we could not record contact information, even if this was in code, we could only have one meeting with each participant. This was not ideal as it compromised the effectiveness of the research. We would not be able to build trust with participants over time, which would affect the extent to which they would be willing to share their experiences with us. As a result, we had to delve into challenging and confidential matters at our first meeting and were unable to clarify details or follow up about particular questions. While we still considered that the project would provide invaluable insight into what it is like to live in Canada with precarious legal status, we felt that a door had been shut.

This inability to conduct a second interview is one of our major concerns with the legal restrictions on being able to promise complete confidentiality to participants. It goes without saying that data regarding precarious situations are rendered sorely incomplete and superficial unless people are willing to tell their stories and share troubling personal experiences. Regardless of legal restrictions, the simple fact remains that people are not willing to share such personal information unless trust is established in a normative manner. This includes a comfortable relationship established over the course of multiple meetings.

Our inability to engage in multiple meetings with participants was a limitation to both projects; however, overlooking this was a decision we made in order to protect our participants from the risk that we would be forced to disclose their identities to authorities.

We also agreed to use a double-blind recruiting process, in which service providers would make potential participants aware of the project and provide them 
Researching Precarious Legal Status 25

with our contact information; it was left up to the individuals to contact the researchers directly if they decided to take part in either project. In effect, this removed service providers from a position where they might have to provide authorities with participants' contact information as they would not know who had participated. This was a significant compromise in that it severely reduced the number of participants that could be interviewed. Without the accompaniment through the process of the service providers whom they trusted, few people called the university number. Those that called often did not speak English and could not communicate with the research assistant that answered the phone. We had originally hoped for 1700 surveys and 250 interviews in the full-scale version of the project. The number of people who participated in the pilot study was 18 .

Having to read the long and legalistic consent form to the participants was very off-putting as well. They had trouble focusing on certain parts and it created a distance between them and the researchers (for the effects of consent form wording on low response rates, see Greyson \& Myles, 2005). The reading of the form was awkward and uncomfortable for all particularly when having to tell people that 'confidentiality will be protected to the extent that the law allows.' We used this phrasing in the informed consent agreement because we were not retaining contact information of participants; however, we continue to be concerned about the legal restrictions on promising confidentiality in academic research.

\section{Concerns about Researchers' Publication and Tenure}

Besides the significant compromises being imposed on our research, another important implication was that going through the process of multiple consultations and modifications took its toll on some of the members of our research team. A significant consideration for researchers was how the work would be viewed when 
articles about it were submitted to academic journals. These were not only philosophical issues, but professional concerns.

One of the ways that today's competitive academic system judges professional competence is based on publication in peer-reviewed academic journals. The system is such that faculty members who have not published sufficiently in peerreviewed journals will be unlikely to be awarded tenure or promotion. This process, colloquially referred to in academic circles as 'publish-or-perish', determines that it is publication in such journals that effectively governs professional development or stagnation. The requirements of these journals significantly affect how faculty members choose to spend their time. Unless their research is likely to meet publication standards, researchers might avoid certain issues -- whether the public would benefit from such research or not.

Academic journals look for evidence of rigorous study in conditions such as random selection of participants, control groups, and measures to ensure the reliability of the data. For qualitative studies, journal editors look for analysis of data that has nuance and complexity, indicating a 'thick description' that goes deep into the worlds of those being interviewed. The compromises we made on methodology, by electing not to do follow-up interviews with participants, left academic members of the team at risk that the research would not be accepted for publication in an academic, peer-reviewed journal ${ }^{7}$.

The tenure clock was also a factor for some professors who were involved with the project. Delays in research timelines can affect tenure, promotion, and

7 These are journals that recruit experts in the field to review manuscripts without knowing who wrote them. Authors are then either rejected or required to make changes to their manuscripts in accord with these reviews. The anonymity of both authors and reviewers ensures that the process is fair and scientifically rigorous. 
Researching Precarious Legal Status 27

publications. As our lengthy process drew on, at least one team member began to wonder about the desirability of dealing with such 'difficult' questions. Others, however, became even more convinced of the need to find a way to carry out the work despite - or because of - the lengthy deliberations and numerous obstacles encountered. While this paper focuses on our experiences of negotiating the conflicting imperatives of our research agenda, the ethics review process, and the Canadian legal framework, there is no question in our minds that the difficulties we confronted around the question of confidentiality were connected to the larger environment of knowledge production. The fact that the larger version of the project was not funded by the federal research council suggested to us that there were additional factors at play in preventing researchers from asking certain questions and engaging with particular populations (Piper \& Sikes, 2008).

\section{Research Incomplete}

Our team was struggling with three competing imperatives: a) our commitment to the subject of precarious status and the academic quality of our work, in terms of concerns with depth and authenticity, b) the moral and ethical obligations to our participants, and c) our obligations to the Canadian legal system. Nonetheless, the many important insights gained from our two studies only indicated further the need for more extensive work of this kind. Although small in scale, both projects offered insights into what it is like to live in Toronto with precarious legal status.

For example, data made clear that a system of differential rights, entitlements, and outcomes is made acceptable by being framed in policy and public understandings through the black-and-white lens of formal citizenship status. Had we been able to conduct multiple interview sessions with our participants, we would have been able to delve into how families organize themselves under these 
Researching Precarious Legal Status 28

legal constraints. How do they remain connected to their communities of origin without being able to physically travel across the border? How do they explain to their children that they should not try out for school sports teams because this may result in school request for a health insurance card? How do they support their children's educational aspirations without telling them that once they complete high school, all doors for further study will be closed to them $?^{8}$ Examining these questions empirically would require an atmosphere of continuity, trust and empathy.

Further, although we had heard anecdotes about Canadian-born children who stay home from school year after year because of their parents' legal status, we were not able to provide such documentation. In situations of spousal abuse, we were unable to garner information about what women do when they fear accessing a shelter. When people live with anger and fear for extended periods, these emotions can eventually explode in negative ways. The children who stay home year after year may turn to gangs as a way to find community; the woman who has nowhere to go and nothing to lose may resort to desperate measures to protect herself and her loved ones. Many questions remain about how the process of negotiating legal status affects personal relationships between partners and within families. Legal-academic constraints limiting our research prevented us from being able to explore these issues.

As mentioned earlier, the limited amount of information available about living with precarious status in Canada is unfortunate because knowing more about the substantial segment of the population that lives with varying degrees of legal status could affect government decisions and allocations as well as inform political

\footnotetext{
${ }^{8}$ Without permanent resident status in Canada, students are required to pay international student fees to attend post-secondary school. These high fees would effectively exclude such students from continuing their education after high school.
} 
mobilization and activism.

\section{Conclusion}

Researchers, secure in their own unquestioned legal status, might assume that the main challenges in carrying out a project with people living with precarious legal status will be gaining the trust of people who wish to stay below the radar of immigration enforcement authorities. What we discovered through our work was that many of the challenges involved in such research occur before one ever 'enters the field' to conduct surveys, interviews, or focus groups. In our negotiations with the ethics review board, we confronted the myth of confidentiality head on and had to make decisions that shaped the outcomes of the research.

Much of our experience resonated with the observations of Bledsoe and colleagues (2007) who noted how the human subjects review system 'regulates creativity':

Facing demands that spiral to the level of sheer impracticality, faculty and students at many institutions face a stark choice: to conduct innovative research in their fields or to meet the requirements of their institutions' IRBs [ERB in Canada].... This strikes to the core of the research enterprise (pp. 594-596). Academic researchers facing such options are in an untenable position. On the one hand, researchers face the threat of being served with a subpoena to disclose the names and phone numbers of those interviewed and being responsible for a person's life falling apart because of detention or deportation. On the other hand, researchers face the moral, academic, and professional dilemmas inherent in being unable to do an individual's experiences justice because she or he may be safely interviewed once and only once.

The idea that it is necessary to warn prospective research participants of the 
Researching Precarious Legal Status 30 legal limits of confidentiality also seriously limits the viability of this type of project. If researchers have to indicate that confidentiality is not possible, that it is a myth, this could mean the end of any potential for research on people living with precarious status. Not being legally able to protect participants' confidentiality undermines our efforts to understand their situations. Confidentiality and security are often intertwined, as the initially successful use of the Wigmore defence by CSIS in protecting its human sources in the security certificate case discussed above indicates. As researchers, community workers, and inhabitants of Canada, we must continue to ask, whose security and confidentiality are deemed to be worthy of protection, to what extent, and by what means? Our negotiations of the ethics review process suggested that if put to the test (e.g., through a Wigmore defence if our records were subpoenaed), the confidentiality and security of people living with precarious immigration status in Canada would fail to be protected.

Although participants in our two studies were willing to take part in research into their precarious legal situations, meeting the approval of the ERB holding our grant led to unexpectedly lengthy and complex negotiations that took a toll on our research team. After extensive consultations, we decided not to put a Wigmore defense to the test but agreed to reconsider it if the long-term project was funded. As the larger project was not funded by the Canadian government, this raises a host of further questions about what research is considered important, what gets funded, and what is seen as too controversial (for an elaboration of how ethics boards and funders influence such decisions, see Sikes \& Piper, 2008). Despite taking note of the importance of the topic and providing a developmental grant that allowed us to carry out the pilot study, the funding body twice refused to support a more thorough investigation of precarious legal status in Canada. 
Researching Precarious Legal Status 31

In particular, ethics review boards must find ways to devise appropriate protocols in order for immigration researchers to be able to recruit families in settings where they are likely to be living with precarious legal status. Before committing to submit a funding proposal in the area, researchers have to know what to expect in terms of timelines, requirements, risk mitigation methods, and legal protection if given a subpoena to appear in court. However, under current prohibitive legal-academic circumstances, the phenomenon of how families experience living with precarious status is difficult to study and has remained under-researched.

Canada is known worldwide as a nation of immigrants built through the labour and effort of people who were born elsewhere in the world. Beyond ignoring the violent colonial establishment of the country, this image and the accompanying national narratives of multiculturalism, celebration of diversity, and humanitarianism masks the fact that many individuals live in Canada long-term without having access to the privileges and protections that come with permanent legal status (although we recognize that in practice many citizens and permanent residents are neither privileged nor protected).

In this paper we have illustrated how the ethics review board at one university tried to facilitate such research while prioritizing the protection of participants who are in a vulnerable position in relation to the state. Due to the "myth of confidentiality' with respect to participants who are of interest to particular authorities, the voices of those who are most marginalized were not heard. A new paradigm is needed to evaluate research projects involving participants who are in a vulnerable position in relation to the state. 
Researching Precarious Legal Status 32

\section{References}

Access Alliance Multicultural Community Health Centre (AAMCHC). (2005).

Racialised groups and health status: A literature review exploring poverty, housing, race-based discrimination and access to health care as determinants of health for racialised groups. Toronto: Access Alliance Multicultural Community Health Centre.

Arat-Koc, S. (1992). Immigration policies, migrant domestic workers, and the definition of citizenship in Canada. In V. Satzewich (Ed.), Deconstructing a nation: Immigration, multiculturalism and racism in '90s Canada (229-242). Halifax: Fernwood.

Bannerman, M., Hoa, P., \& Male, R. (2003). South Riverdale Community Health Centre's exploration of services for non-insured people in East Toronto. Toronto: South Riverdale Community Health Centre.

Bean, F.D., Corona, R., Tuiran, R, Woodrow-Lafield, K.A., \& Van Hook, J. (2001). Circular, invisible, and ambiguous migrants: Components of difference in estimates of the number of unauthorized Mexican migrants in the United States. Demography 38(3): 411-422.

Berinstein, C., McDonald, J., Nyers, P., Wright, C, \& Zerehi, S. (2006). “Access Not Fear": Non-Status Immigrants and City Services. Retrieved April 19, 2006, from: http://www.dadttoronto.org/members/publications/Access\%20Not\%20Fear\%20Rep ort\%20(Feb\%202006).pdf

Berk, M.L., \& Schur, C.L. 2001. The effect of fear on access to care among undocumented Latino immigrants. Journal of Immigrant Health, 3(3), 151-156.

Bernhard, J.K., Goldring, L., Young, J., Wilson, B., \& Berinstein, C. (2007). Living 
Researching Precarious Legal Status 33 with precarious legal status in Canada: Implications for the wellbeing of children and families. Refuge, 24(2), 101-114.

Bledsoe, C.H., Sherin B., Galinsky, A.G., Headley, N.M., Heimer, C.A., Kjeldgaard, E., Lindgren, J., Miller, J.D., Roloff, M.E., \& Uttal, D.H. (2007). Regulating creativity: Research and survival in the ERB iron cage. Northwestern University Law Review, 101(2), 593-642.

CBC Radio. (2008). The big commute. The Current, September 23.

Caroll, J., \& Knerr, C. (1975). Confidentiality and social science research sources and data: The Popkin case. Political Science Quarterly, 6, 268-280.

Committee for Accessible AIDS Treatment (CAAT). (2001). Improving access to legal services and health care for people living with HIV/AIDS who are immigrants, refugees or without status. Action Research Report. Toronto: Regent Park Community Health Centre. Retrieved October 23, 2009, from http://www.regentparkchc.org/CAAT\%20com\%20Final\%20report.PDF

Cornelius, W. (1982). Interviewing undocumented immigrants: Methodological reflections based on fieldwork in Mexico and the U.S. San Diego, CA: University of California, San Diego.

Curry, B. (2009). Judge orders CSIS to hand over file. The Globe and Mail, October 20. de Genova, N.P. (2002). Migrant ‘illegality’ and deportability in everyday life. Annual Review of Anthropology (31), 419-447.

Doiron, M. (2005). Personal communication, July 12.

Don't Ask, Don't Tell Campaign (DADT). (2005, Winter). Immigration status? Don't ask, don't tell. Toronto.

Dyer, S., \& Demeritt, D. (2009). Un-ethical review? Why it is wrong to apply the medical model of research governance to human geography. Progress in Human 
Geography 33(1): 46-64.

Goldring, L., Berinstein, C., \& Bernhard, J. (2009). Institutionalizing precarious migratory status in Canada. Citizenship Studies, 13(3), 239-265.

Greyson, J.P., \& Miles, R. (2005). How research ethics boards are undermining survey research on Canadian university students. Journal of Academic Ethics, 2, 293-314.

Hall, P.A., \& Lamont, M. (Eds.). (2009). Successful societies: How institutions and culture affect health. Cambridge: Cambridge University Press.

Hare, F. G. (2007). Transition without status. The experience of youth leaving care without Canadian citizenship. New Directions for Youth Development, (113), 77-88.

Jimenez, M. (2003). 200,000 illegal immigrants toiling in Canada's underground economy. The Globe and Mail. November 15.

Khandor, E., McDonald, J., Nyers, P., \& Wright, C. (2004). The regularization of nonstatus immigrants in Canada 1960-2004: Past policies, current perspectives, active campaigns. Toronto: STATUS Campaign.

Lempert, R.O., \& Saltzburg, S.A. (1982). A modern approach to evidence. Text, problems, transcripts, and cases ( $2^{\text {nd }}$ ed.). St. Paul, MN: West Publishing Company.

Lessard, G., \& L. Ku. (2003). Gaps in coverage for children in immigrant families. The Future of Children, 13(1), 100-115.

Lindgreen, J. (2002). Discussion: Anticipating problems: Doing social science research in the shadow of the law. Sociological Methodology, 32(1), 29-32.

Lowman, J., \& Palys, T. (2001). The ethics and law of confidentiality in criminal justice research: A comparison of Canada and the United States. International Criminal Justice Review, 11, 1-33.

Macklin, A. (2001). Borderline security. In R.J. Daniels, P. Macklem, \& K. Roach 
Researching Precarious Legal Status 35

(Eds.), The security of freedom: Essays on Canada's anti-terrorism bill (383-404).

Toronto: University of Toronto Press.

Menjivar, C. (2006). Liminal legality: Salvadoran and Guatemalan immigrants' lives in the United States. American Journal of Sociology, 111(4), 999-1037.

Nyers, P. (2003). Abject cosmopolitanism: The politics of protection in the antideportation movement. Third World Quarterly, 24(6), 1069-1093.

Palys, T. (2005). Personal communication. June 29, 30.

Platform for International Cooperation on Undocumented Migrants (PICUM) (2009). Report of PICUM's international conference on undocumented children in Europe: Invisible victims of immigration restrictions. Retrieved on April 28, 2009 from WWW. picum.org

Pratt, G. in collaboration with The Philippine Women Centre (2003). From migrant to immigrant: Domestic workers settle in Vancouver, Canada. Research on Immigration and Integration in the Metropolis Working Paper Series No. 03-18.

Robertson, G. (2005). Canada has no handle on illegal immigrant workers. Edmonton Journal, May 30, A5.

San Martin, R. M. (2004). Unwanted in paradise: Undocumented migrant women sexworkers in Toronto. In R. B. Folson (Ed.), Calculated kindness: Global restructuring, immigration and settlement in Canada (pp.71-83). Black Point, NS: Fernwood Publishing.

Schmitz, C. (2009). Federal Court recognizes new 'covert informer' shield in security certificate case. Lawyer's Weekly. Ottawa, Ontario. March 13.

Schwenken, H. (2003). RESPECT for all: The political self-organization of female migrant domestic workers in the European Union. Refuge, 21(3), 45-52.

Sharma, N. (2006). Home economics: Nationalism and the making of 'migrant workers' 
in Canada. Toronto: University of Toronto Press.

Sikes, P., \& Piper, H. (2008). Risky research or researching risk: the role of ethics review, in J. Satterthwaite, M. Watts and H. Piper, (Eds.), Talking truth, confronting power. Stoke on Trent: Trentham.

Stark, L. J. M. (2006). Morality in science: How research is evaluated in the age of human subjects regulation. Princeton University: Unpublished Ph.D. Dissertation.

Stasiulis, D. K., \& Bakan, A. B. (2005). Negotiating citizenship: Migrant women in Canada and the global system. Toronto: University of Toronto Press.

Suárez-Orozco, C. \& Suárez-Orozco, M. (2001). Children of immigration. Cambridge, MA: Harvard University Press.

United Nations. (1990). Convention on the rights of the child. Retrieved October 23, 2009, from http://www2.ohchr.org/english/law/crc.htm.

Valiani, S. (2009). The shift in Canadian immigration policy and unheeded lessons of the Live-in Caregiver Program (LCP). Retrieved September 30, 2009, from: http://www.ccsl.carleton.ca/ dana/TempPermLCPFINAL.pdf.

Walters, W. (2002). Deportation, expulsion, and the international police of aliens. Citizenship Studies, 6(3), 265-292.

Wigmore, J. H. (1905). A treatise on the system of evidence in trials at common law, including the statuses and judicial decisions of all jurisdictions of the United States, England and Canada. Boston: Little, Brown and Company.

Wright, C. (2003). Moments of emergence: Organizing by and with undocumented and non-citizen people in Canada after September 11. Refuge, 21(3), 5-15.

Yau, M. (1995). Refugee students in Toronto schools: An exploratory study. Toronto: Research Department of Toronto Board of Education.

Young, J.E.E. (2005). 'This is my life': Questions of agency and belonging among youth 
living with less than full status. Unpublished master's major research paper, Ryerson University, Toronto.

Young, J.E.E. (forthcoming). 'A new politics of the city': Locating the limits of hospitality and looking to the practice of the city-as-refuge. $A C M E$ : $A n$ International E-Journal for Critical Geographies. 